\section{Tuberculosis 2015: burden, challenges and strategy for control and elimination}

\author{
Mario Raviglione, ${ }^{1}$ Giorgia Sulis ${ }^{2}$ \\ ${ }^{1}$ Global Tuberculosis Programme, World \\ Health Organization, Geneva, \\ Switzerland; 'Department of Infectious \\ and Tropical Diseases, WHO \\ Collaborating Centre for TB/HIV coinfec- \\ tion and for TB Elimination, University of \\ Brescia, Italy
}

\section{Abstract}

Tuberculosis (TB) is a leading cause of morbidity and mortality worldwide, accounting for about 9.6 million new cases and 1.5 million deaths annually. The poorest and socially excluded groups carry the largest burden of disease, which makes it essential to properly address the social determinants of health through poverty reduction measures and targeted interventions on high-risk populations. The spread of multidrug-resistance TB requires special attention and highlights the need to foster research on TB diagnostics, new drugs and vaccines. Although many advances have been made in the fight against TB over the last twenty years, a lot is still needed to achieve global elimination. The new end-TB strategy that was first launched in 2014 by the World Health Organization, is fully in line with the seventeen Sustainable Development Goals that came into effect since January 2016 and sets ambitious goals for the post-2015 agenda. A 90\% reduction in TB-related mortality and an $80 \%$ decline in TB incidence within 2030 as well as the abolition of catastrophic expenditures for TB-affected people are the main targets of this strategy. Strong government commitment and adequate financing from all countries together with community engagement and appropriate investments in research are necessary in order to reach these objectives.

\section{Introduction}

In 2016, tuberculosis (TB) is still a major cause of death and suffering worldwide. Its control is a global public health issue and therefore needs to be conceived and carried out along with the basic principles of equity, human right to health and social protection. As marginalized people are always greatly exposed to health problems and often face difficulties in accessing care, social and econom- ic determinants of ill health must be appropriately addressed together with adequate implementation of the specific interventions available today to combat those diseases that disproportionally affect the poorest. Similarly to what observed for other infectious diseases, TB epidemiology is closely connected with social and economic conditions which makes TB prevention, care and control even more challenging. ${ }^{1}$ Poverty reduction has been recognized as a global priority by the United Nations and other International Organizations since many decades, but it was only when the Millennium Development Goals (MDGs) were first launched in 2000 that this issue was actually put in the spotlight. The MDGs, in short, called upon all governments to join forces to combat poverty and its consequences, including health conditions like TB, in order to foster development of societies and nations. In this context, community engagement played a pivotal role in reaching the most vulnerable groups, assessing their specific needs and promoting active mobilization of society.

In this paper we will discuss the main aspects of TB epidemiology at global level as well as the threat of multidrug resistances. Current achievements, future challenges, and prevention and control strategies in the context of the new Sustainable Development Goals (SDGs) will also be examined.

\section{The global burden of tuberculosis}

Tuberculosis ranks alongside HIV/AIDS as the top infectious killer worldwide, with 9.6 million new incident cases and 1.5 million deaths estimated to have occurred in $2014 .{ }^{2}$ Of note, more than two thirds of the global TB burden is reported in Africa and Asia, and in absolute terms India, Indonesia and China account for the highest number of TB cases amounting to $43 \%$ of the global burden.

The human immunodeficiency virus (HIV) is the strongest risk factor for TB, and TB is the first cause of death among people living with HIV (PLHIV), even in an era of scale up of antiretroviral therapy (ART), causing one third of all HIV-related deaths. In 2014, HIV-infected persons accounted for 1.2 million (12\%) of the estimated 9.6 million people globally who developed TB. At the end of the same year, TB contributed to one third of the 1.2 million deaths from HIV/AIDS and HIV was responsible for $25 \%$ of the 1.5 million TB deaths. ${ }^{2}$ The majority (nearly three quarters) of these estimated HIV-associated TB cases and deaths are in the African Region, with eastern and southern African countries carrying most of the global burden. ART coverage among known HIV-infected TB patients in 2014 was $77 \%$,
Correspondence: Giorgia Sulis, Department of Infectious and Tropical Diseases, WHO Collaborating Centre for TB/HIV coinfection and for TB Elimination, University of Brescia, P.le Spedali Civili 1, 25123, Brescia, Italy.

Tel.: +39.030.3995677 - Fax: +39.030 .3996084 .

E-mail: g.sulis@unibs.it

Key words: Tuberculosis control; elimination; tuberculosis epidemiology; end-tuberculosis strategy.

Contributions: the authors contributed equally.

Conflict of interest: the authors declare no potential conflict of interest.

Received for publication: 29 April 2016. Accepted for publication: 29 April 2016.

This work is licensed under a Creative Commons Attribution-NonCommercial 4.0 International License (CC BY-NC 4.0).

(C) Copyright M. Raviglione and G.Sulis, 2016

Licensee PAGEPress, Italy

Infectious Disease Reports 2016; 8:6570

doi:10.4081/idr.2016.6570

which represents a further increase from previous years, but it is still far from the World Health Organization (WHO) recommendation that all HIV-positive people with TB should receive it. ${ }^{3,4}$ Other co-morbidities such as those related to diabetes mellitus, smoking, and alcohol abuse are currently emerging in high, middle and low-income countries as potentially associated with a greater risk of progression from latent TB infection (LTBI) to active disease (two to three-fold higher in diabetics and smokers, for instance) as well as a less favorable treatment outcome. ${ }^{5}$

Multidrug resistant tuberculosis (MDR-TB), defined as resistance to, at least, rifampin and isoniazid (the most commonly used and potent drugs of the currently recommended first-line therapeutic regimen), represents another important threat in the fight against the disease. The emergence and spread of drug resistances mostly derive from mismanagement of TB cases such as the use of inappropriate dosages, inappropriate regimens, limited availability of quality-assured pharmaceutical products, and little efforts to support patient's adherence. Approximately 480,000 newly emerging cases of MDR-TB are estimated to occur every year. However, the proportion of cases detected and notified is only about a quarter of those estimated due to low implementation of drug susceptibility testing especially in resource-limited settings. The distribution of MDR-TB cases is geographically uneven (Figure 1), with countries of the former Soviet Union reporting the highest per- 
centages (up to 35\%) and five countries (India, China, Russia, Pakistan and Ukraine) accounting for as much as $60 \%$ of the global caseload in absolute terms. ${ }^{2}$

\section{Achievement of global targets}

In September 2000 the United Nations General Assembly adopted an historical resolution, best known as the Millennium Declaration. ${ }^{6}$ This sent a strong signal to all countries and communities in an attempt to change their behaviors, socio-political choices and health responses based on the fundamental principles of freedom, equality, solidarity, tolerance, respect for nature and shared responsibility. Eight goals to be achieved within the following fifteen years were identified. Three of them were devoted to health issues, and MDG 6 specifically addressed the three global epidemics of HIV/AIDS, malaria and TB. In particular, the TB-relevant target as defined in the MDG framework was to halt and begin to reverse the incidence by 2015 . This target has been achieved both globally and in all six WHO Regions, with 43 million lives estimated to have been saved between 2000 and 2014 (Figure 2). Through effective prevention, quality-assured diagnosis and proper treatment the burden of TB has therefore decreased. ${ }^{7}$ Additionally, a 47\% drop in TB mortality rates has been estimated since 1990, which means that the international goal of mortality reduction has almost been met. However, incidence is falling too slowly, with a $1.5 \%$ per year declining rate, which is far from sufficient to reach the future targets. Importantly, while an average $86 \%$ cure rate has been attained at global level among new TB cases, some countries, like those in Eastern Europe, have documented much lower treatment success due to the high prevalence of MDR-TB. With respect to TB/HIV co-infection, assessment of achievements shows that significant progress has been made through the implementation of TB/HIV collaborative activities since 2005 , with an estimated over 5 million lives saved up to now.

\section{The challenges of tuberculosis control}

If we look at the future challenges of TB control, five priorities for action can be delineated.

First of all, around 3.6 million TB cases are estimated to be missing every year comparing with the estimated figure; this means that they are not diagnosed and/or notified to public health systems. ${ }^{8}$ All such unknown cases may be diagnosed and treated but not reported, or simply never detected. This constitutes both an individual care and a transmission problem, as their outcomes may not be favorable and they may be responsible for continuous transmission thus representing a major public health concern.

Secondly, MDR-TB must be addressed as a crisis given its potential for hindering the achievement of current objectives. Newly available rapid molecular diagnostics need to be expanded at the lowest possible care level and new medicines, such as bedaquiline and delamanid, added to current regimens to improve care of drug-resistant cases and prevent them from spreading further. ${ }^{9}$

Third, the co-epidemic of TB/HIV requires an accelerated response based on a deeper and more comprehensive integration of services between often separately managed programs. ${ }^{10}$ The Global Fund and other key stakeholders have expressed concerns about the limited coverage of collaborative TB/HIV activities within grants of the Global Fund and other initiatives, and called for measures for improvement. This has led to the development of unified concept notes (i.e., proposals by countries applying for external financing) aimed to better address the dual epidemic through a more service-integrated approach. ${ }^{11}$

Fourth, financial support to the fight against TB is pivotal to close the resource gap. About 8 billion US $\$$ are annually required to cover the ordinary costs of case detection and treatment worldwide, but available funds, in the range of 6.4 billion US $\$$, are not enough to address such needs (Figure 3 ). ${ }^{2}$

Last but not least, research needs to be intensified along the entire spectrum from basic towards the development pipelines and operational research, in order to successfully result in new diagnostics, drugs and eventually vaccines and the rapid uptake of such innovations. To this purpose, new investments from research institutions, governments and the corporate sector need to fill a gap that is esti-

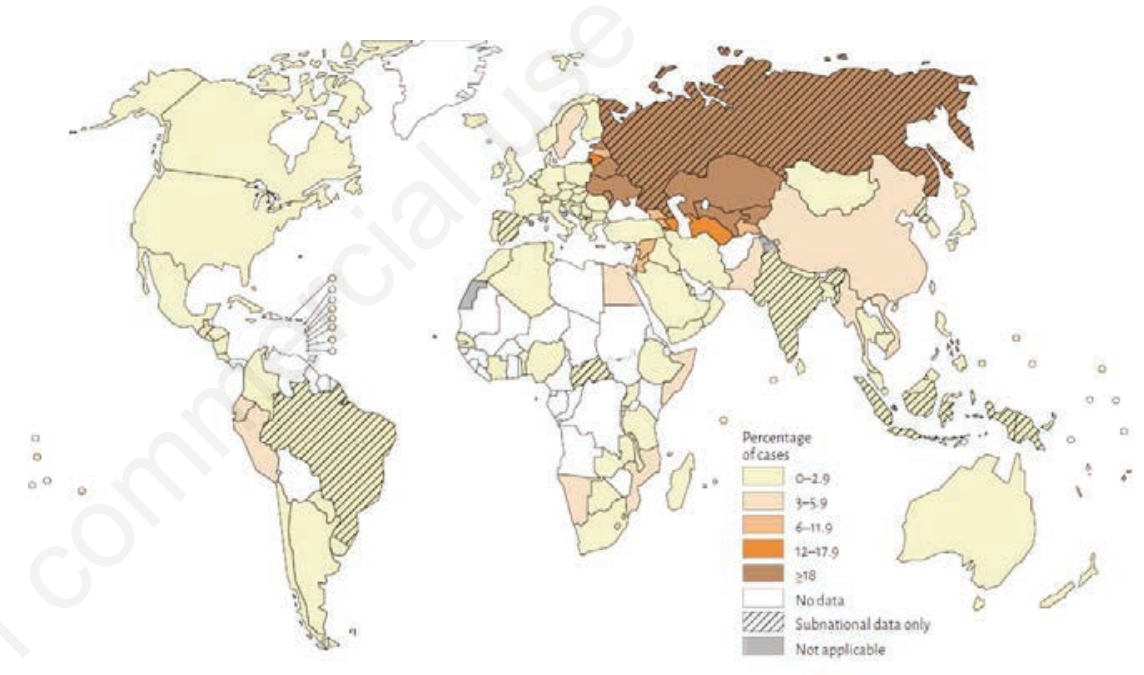

Figure 1. Percentage of new tuberculosis cases with MDR-T/B, 2015. Reproduced with permission from Global Tuberculosis Report 2015, WHO.²
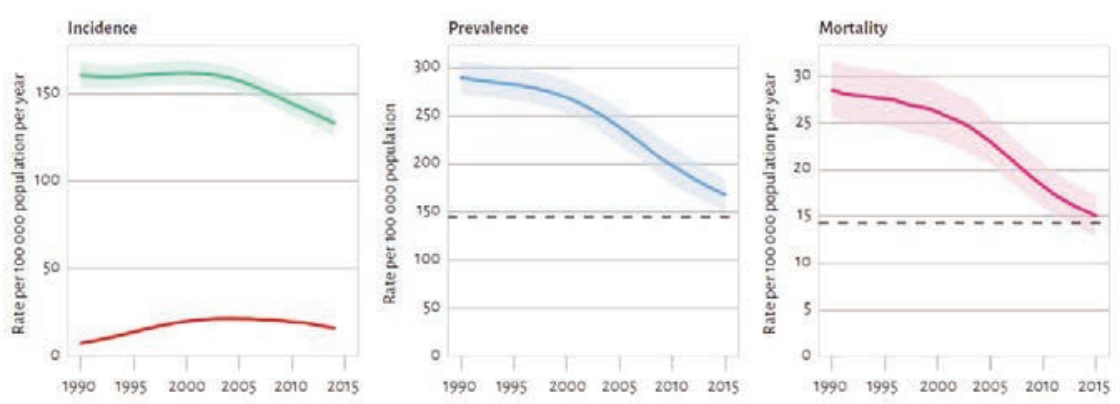

Figure 2. Trends in tuberculosis incidence (the red line refers to incident cases among HIV-infected persons), prevalence and mortality, 1990-2015. Reproduced with permission from Global Tuberculosis Report 2015, WHO.2 
mated to be in the area of at least 1.3 billion US\$ (Figure 3).

\section{The future response to tuber- culosis challenges}

The future response to the challenges outlined above is included in a new set of seventeen Sustainable Development Goals (SDGs) that were recently launched within the post2015 global development agenda to come into effect on January $1^{\text {st }}, 2016$ when they will replace the MDGs. ${ }^{12}$ One of the main differences between SDGs and MDGs lies in the fact that the former ones are universally applied to all countries instead of being focused on the developing world and depending largely upon aid funding. In addition, while the MDGs were limited to some well-defined categorical challenges to face, the SDGs are much broader in their reach, are integrated and indivisible, and rely not only on economic but also on environmental, moral and political considerations. Among the SDGs, Goal 3 (ensure healthy lives and promote well-being for all at all ages) covers a range of health-related issues such as maternal and child health, communicable and non-communicable diseases, and target 3.3 clearly calls for ending the major global epidemics (HIV, TB, malaria, neglected tropical diseases) by 2030.13 This is fully in line with what stated in May 2014 by the $67^{\text {th }}$ World Health Assembly through a resolution that contains the new global WHO's End TB Strategy and its ambitious targets. ${ }^{14}$ The vision behind the new strategy is a TB-free world, with no more people suffering from the disease or dying because of it. Targets for 2035 include a 95\% decline in TB mortality, a $90 \%$ reduction in TB incidence rate (to less than 10 cases per
100,000 population globally) and, to align with the quest for universal health coverage and social protection, the complete abolition of catand families. Broad poverty alleviation measures are therefore strongly expected to effectively overcome the impediments and cut down the barriers in access to healthcare. ${ }^{15,16}$

Furthermore, some milestones have been introduced every five years along the pathway up to 2035: in particular, coinciding with the SDG deadline of 2030, the number of TB deaths should be reduced by $90 \%$ and TB incidence rate should decline by $80 \%$, compared to the baseline at 2015 , by 2030 . Of note, there is an additional high-level target of zero catastrophic costs that should be achieved already in $2020 .{ }^{17}$

\section{The END-TB strategy}

The new strategy stands on three pillars and is based on four cross-cutting principles defined as follows: i) government stewardship and accountability, with monitoring and evalu-

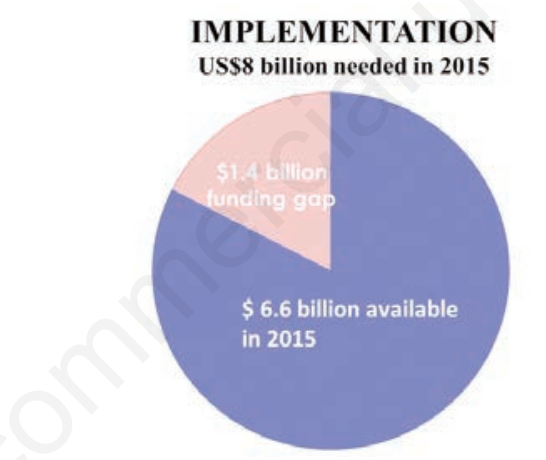
astrophic expenditures for TB-affected people

ation; ii) building a strong coalition with civil society and communities; iii) protecting and promoting human rights, ethics and equity; iv) adaptation of the strategy and targets at country level, with global collaboration (Table 1). ${ }^{14}$

The first pillar focuses on care aspects that are specific to TB. It refers to integrated, patient-centered care and prevention, and underlines the need to clearly identify the most vulnerable groups in a population in order to address their needs as a priority. Active case finding along with drug susceptibility testing for resistance detection are among the core components of this pillar as are the concepts of treatment for all, including drug-resistant cases and children. Special attention is also devoted to PLHIV, given their high-risk condition, which claims for tailored interventions involving the provision of combined treatments for both diseases as well as the implementation of appropriate preventive measures. Finally, preventive therapy to be administered to people at high risk is emphasized as a tool to prevent disease among the pool of latently infected people.

The second pillar calls for bold policies and supportive systems to be based on a strong

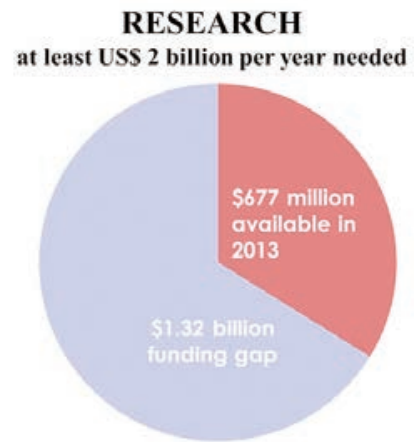

Figure 3. Tuberculosis financing and funding gaps, 2014. Adapted with permission from Global Tuberculosis Report 2015, WHO. ${ }^{2}$

Table 1. End tuberculosis strategy: vision, targets and pillars and principles.

\begin{tabular}{ll}
\hline Vision & A world free of TB (zero deaths, disease and suffering due to tuberculosis) \\
Goal & End the global TB epidemic \\
\hline Targets for 2035 & $\begin{array}{l}95 \% \text { reduction in TB deaths (compared with 2015); 90\% reduction in TB incidence rate (less than } 100 \text { TB cases per million } \\
\text { population); no affected families facing catastrophic costs due to TB }\end{array}$ \\
Principles & Government stewardship and accountability, with monitoring and evaluation; strong coalition with civil society organizations and \\
& communities; protection and promotion of human rights, ethics and equity; adaptation of the strategy and targets at country level, \\
& with global collaboration.
\end{tabular}


political commitment, greater financing, extended community engagement, active cooperation with non-governmental organizations as well as the civil society and public and private institutions. Universal health coverage and social protection represent the cornerstones of the post-2015 broader agenda for effective health systems delivering the necessary services to people. Although it is essential that TB diagnosis and treatment are provided free of charge to all people irrespective of their living area, other costs such as those related to travel to reach the healthcare facilities or those produced by the loss of working days must be taken into account to properly define the financial consequences of TB on affected patients. ${ }^{18}$ This pillar also emphasizes the broader policies that must be in place for any disease control effort to succeed.

The third pillar underlines the importance of intensified research and innovation to make a real change in current TB trends. In order to achieve the ambitious targets of the End-TB strategy, the rate of decline of global TB incidence must increase to at least $10 \%$ per year by 2015. Similar declining rates were reached in some European countries in the mid twentieth century, following the introduction of the first anti-TB drugs compounded with the significant improvement of general living conditions. The development of better diagnostics (including new point-of-care tests), safer, easier and shorter treatment regimens for active TB and LTBI, and effective pre- and post-exposure vaccines are critical to break the trajectory of the TB epidemic and further accelerate the reduction of TB incidence after 2025. Without new effective tools it will not be possible to accelerate incidence decline at $17 \%$ per year, which is necessary to achieve the 2035 targets. ${ }^{19,20}$

\section{Tuberculosis research: what is needed?}

New diagnostic tools are particularly awaited in order to improve the diagnosis of disease and latent infection, the rapid detection of drug-resistance, and for use in the pediatric population. Several new diagnostics or diagnostic methods have been endorsed by the WHO since 2007 and many others are under investigation. Whole-genome sequencing is being studied in an attempt to identify relevant mutations that could predict drug resistance: this approach may be potentially useful together with routine diagnostic tests in order to build up individualized therapeutic schemes in severe cases of MDR-TB and extensively drugresistant TB (XDR-TB). ${ }^{21}$ A number of new molecules are currently in the early phases of the development pipeline although it will probably take about a decade to put them into the market, provided that their efficacy and safety will be demonstrated. ${ }^{22,23}$ After many years of financially limited research, two new drugs for MDR-TB (bedaquiline and delamanid) were approved between 2012 and 2013. These two drugs may save lives although they will probably yield a little impact of the global epidemiology of TB for which shorter and more effective regimens for both drug-susceptible disease and latent infection are necessary. ${ }^{23-25}$ Vaccines may eventually be the most effective response to TB but the development of effective vaccines is considerably hindered by the complex biology of mycobacteria, whose nature is still partially undefined. ${ }^{26,27} \mathrm{BCG}$, which was first introduced in 1921, is the only currently available vaccine, mostly unsuitable for preventing infection and TB disease and therefore with limited use in specific contexts and for specific target populations (such as children in the first 2-3 years of life where it prevents wide dissemination of bacilli following exposure). ${ }^{28,29}$

\section{Concluding remarks}

Looking beyond 2015, ending the TB epidemic is one of the best returns in investments. As recently highlighted in The Economist (Development: the economics of optimism; issued on Jan 24, 2015), reducing the deaths from tuberculosis would allow to gain an average 43 US dollars per dollar spent. Lowering the burden of this disease therefore represents a high-impact and cost-effective poverty alleviation measure, more than many other health interventions, which is consistent with the close linkages existing between TB and impoverishment.

Although the MDG target of reversing trends in TB epidemiology has been met, the global burden remains enormous with several challenges that need to be properly addressed: we can and we definitely have to do more in TB control. Global elimination in the next few decades can eventually come true in spite of the long and hard way towards it.

\section{References}

1. Lacerda SNB, de Abreu Temoteo RC, Monteiro de Figueiredo TMR, et al. Individual and social vulnerabilities upon acquiring tuberculosis: a literature systematic review. Int Arch Med 2014;7:35.

2. World Health Organization. Global tuberculosis report 2015. Available from: http://apps.who.int/iris/bitstream/10665/19 1102/1/9789241565059_eng.pdf?ua=1. Accessed: October 2015.

3. Kerschberger B, Hilderbrand K, Boulle AM, et al. The effect of complete integration of HIV and TB services on time to initiation of antiretroviral therapy: a before-after study. PLoS One 2012;7:e46988.

4. World Health Organization. Consolidated guidelines on the use of antiretroviral drugs for treating and preventing HIV infection: recommendations for a public health approach. 2013. Available from: http://www.who.int/iris/bitstream/10665/85 321/1/9789241505727_eng.pdf?ua=1. Accessed: October 2015.

5. Sotgiu G, Matteelli A, Migliori GB. Diabetes and tuberculosis: what else beyond? Behaviour and information technology. Int J Tuberc Lung Dis 2015;19: 1127-8.

6. United Nations General Assembly. United Nations Millennium Declaration, Resolution Adopted by the General Assembly, 2000, A/RES/55/2. Available from: http://www.refworld.org/docid/ 3b00f4ea3.html. Accessed: October 2015.

7. Lomazzi M, Borisch B, Laaser U. The millennium development goals: experiences, achievements and what's next. Glob Health Action 2014;7:2369.

8. Herbert N, George A, Baroness Masham of I, et al. World TB Day 2014: finding the missing 3 million. Lancet 2014;383:1016-8.

9. Falzon D, Mirzayev F, Wares F, et al. Multidrug-resistant tuberculosis around the world: what progress has been made? Eur Respir J 2015;45:150-60.

10. World Health Organization. WHO policy on TB/HIV collaborative activities: guidelines for national programmes and other stakeholders. 2012. Available from: http://apps.who.int/iris/bitstream/10665/44 789/1/9789241503006_eng.pdf?ua=1\&ua= 1. Accessed: October 2015.

11. Gupta S, Granich R, Date A, et al. Review of policy and status of implementation of collaborative HIV-TB activities in 23 highburden countries. Int J Tuberc Lung Dis 2014;18:1149-58.

12. Murray CJ. Shifting to sustainable development goals. Implications for global health. N Engl J Med 2015;373:1390-3.

13. Hill PS, Buse K, Brolan CE, Ooms G. How can health remain central post-2015 in a sustainable development paradigm? Global Health 2014;10:18.

14. World Health Organization. Resolution WHA67/11: Global strategy and targets for tuberculosis prevention, care and control after 2015. 2014. Available from: http://apps.who.int/gb/ebwha/pdf_files/WH A67/A67_11-en.pdf.

15. Touraine M, Gröhe H, Coffie RG, et al. Universal health coverage and the post2015 agenda. Lancet 2014;384:1161-2.

16. Gupta V, Kerry VB, Goosby E, Yates R. Politics and universal health coverage. 
The post-2015 global health agenda. N Engl J Med 2015;373:1189-92.

17. Uplekar M, Weil D, Lonnroth K, et al. WHO's new end TB strategy. Lancet 2015;385:1799-801.

18. Lönnroth K, Glaziou P, Weil D, et al. Beyond UHC: monitoring health and social protection coverage in the context of tuberculosis care and prevention. PLoS Med 2014;11:e1001693.

19. Schito M, Maeurer M, Kim P, et al. Translating the tuberculosis research agenda: much accomplished, but much more to be done. Clin Infect Dis 2015;61:S95-S101.

20. World Health Organization. Global consultation on research for TB elimination. 2014. Available from: http://www.who.int/tb/features_archive/re searchforTBelimination_meeting/en/. Accessed: October 2015.
21. Walker TM, Kohl TA, Omar SV, et al. Wholegenome sequencing for prediction of Mycobacterium tuberculosis drug susceptibility and resistance: a retrospective cohort study. Lancet Infect Dis 2015;15:1193-202.

22. Evangelopoulos D, McHugh TD. Improving the tuberculosis drug development pipeline. Chem Biol Drug Des 2015;86:951-60.

23. Zumla AI, Gillespie SH, Hoelscher M, et al. New antituberculosis drugs, regimens, and adjunct therapies: needs, advances, and future prospects. Lancet Infect Dis 2014;14:327-40.

24. Kakkar AK, Dahiya N. Bedaquiline for the treatment of resistant tuberculosis: promises and pitfalls. Tuberculosis (Edinb) 2014;94:357-62.

25. Gupta R, Geiter LJ, Wells CD, et al. Delamanid for extensively drug-resistant tuberculosis. N Engl J Med 2015;373:291-2.

26. Sotgiu G, Pontali E, Centis R, et al. Delamanid (OPC-67683) for treatment of multi-drug-resistant tuberculosis. Expert Rev Anti Infect Ther 2015;13:305-15.

27. Kaufmann SH, Lange C, Rao M, et al. Progress in tuberculosis vaccine development and host-directed therapies: a state of the art review. Lancet Respir Med 2014;2:301-20.

28. Wilkie ME, McShane H. TB vaccine development: where are we and why is it so difficult? Thorax 2015;70:299-301.

29. Moliva JI, Turner J, Torrelles JB. Prospects in Mycobacterium bovis Bacille Calmette et Guérin (BCG) vaccine diversity and delivery: why does BCG fail to protect against tuberculosis? Vaccine 2015; 33:5035-41. 